\title{
La frontera entre Uruguay y Brasil y la realidad del español en comunidades fronterizas
}

\author{
Hugo Jesús Correa Retamar \\ Claudia Stella Risso ${ }^{* *}$
}

Resumo: A língua espanhola é falada em mais de 21 países e cada um deles nos apresenta uma nova forma de perceber o mundo, logo a riqueza dessa pluralidade e variedade linguística e cultural também deve ser contemplada e valorizada no ensino de idiomas. Estudar uma língua estrangeira não é apenas enfrentarse com uma fonética ou palavras novas, e sim ampliar o leque de possibilidades de atuar no mundo. Assim, neste trabalho, nos dedicaremos a analisar uma dessas realidades onde se fala a língua espanhola, uma realidade desconhecida para muitos e menosprezada por tantos outros, a fronteira entre Uruguai e Brasil, mais estritamente, o convívio linguístico e cultural entre Santana do Livramento-Rivera e Quaraí-Artigas. Os exemplos encontrados são reais e produzidos através da coleta de dados, e o objetivo do trabalho é fazer com que a complexa realidade da fronteira seja entendida e valorizada em sala de aula.

Palavras-chave: Fronteira; DPU; Contato; Espanhol; Português.

Professor de Língua Espanhola do Colégio de Aplicação da UFRGS. Licenciado em Letras pela UFRGS e Mestre em Literaturas de Língua Espanhola pela mesma instituição. E-mail: hojarasca@ig.com.br.

** Professora de Espanhol do Instituto Cervantes de Porto Alegre e acadêmica do curso de Letras (UFRGS). E-mail: risso.claudia@gmail.com 
Resumen: El español es hoy una lengua en más de 21 países y cada uno de ellos presenta nuevas maneras de percibir el mundo, por lo tanto, la riqueza de esta pluralidad y variedad lingüística y cultural debe ser discutida y valorada incluso en el aula de E.L.E. El que estudia una lengua extranjera no solo se enfrenta con una fonética o con palabras nuevas, sino que tiene la posibilidad de ampliar sus formas de actuar en el mundo. Por ello, en este trabajo, nos dedicaremos a analizar una de las tantas realidades que forman el español, lo vivido por las regiones de frontera entre Uruguay y Brasil, más específicamente la convivencia lingüística y cultural entre Santana do Livramente/ Rivera y Quaraí/Artigas, una realidad desconocida para muchos y menospreciada por otros tantos. Los ejemplos que figuran en el trabajo se produjeron a través de la observación y recolección de datos y tienen como objetivo hacer que la compleja realidad de la frontera sea entendida y valorada en el aula.

Palabras clave: Frontera; DPU; Contacto; Español; Portugués.

En términos de lenguas en contacto, la realidad del sur de Brasil es específicamente rica y compleja. En Río Grande do Sul, por ejemplo, se encuentran todavía hoy colonias italianas y alemanas donde la gente todavía mantiene vivos los dialectos oriundos de los países de origen de sus abuelos y bisabuelos desde fines del siglo XIX, época de las respectivas inmigraciones. Sin embargo, si pensamos en la propia geografía del estado sureño nos deparamos con otro tipo de contacto producido por la rutina puerta con puerta de gentes que charlan, pelean, compran, venden, se casan y viven una realidad propia, la realidad del fronterizo. Un ejemplo singular es la relación y el producto de la misma que ocurre entre Uruguay y Brasil, países que tienen más de cinco ciudades en contacto directo y constante debido a su geografía.

Como sabemos, Brasil y Uruguay son dos países latinoamericanos con realidades bastante distintas, el primero, un gigante poderoso aunque con abismos sociales que asustan; el otro, un pequeño país que posee más ganado que habitantes 
por $\mathrm{Km}^{2}$, pero que a la vez es uno de los países de referencia mundial en niveles sociales como por ejemplo en el caso de la tasa de analfabetismo que es aún hoy la más baja de América Latina, el 2\%. Además, a estos dos países los separan límites geográficos, culturales y lingüísticos si tenemos en cuenta zonas identificadas como nítidamente uruguayas o brasileñas como las ciudades de Montevideo y São Paulo. Sin embargo, cuando los límites geográficos e históricos ya no son tan nítidos la identidad de determinados territorios es más bien singular.

Lo que hoy se conoce como Uruguay y Brasil es el resultado de un largo proceso de más de cuatro siglos de historia. La frontera entre estos dos países forma parte de este proceso, ya que hasta la mitad del siglo XIX no estaban del todo demarcados los lindes entre ambos. De algún modo, este pasado complejo se hace presente incluso en la realidad actual de los ciudadanos de zonas fronterizas como ocurre en las comunidades de Rivera (R.O.U. ${ }^{1}$ ) y Santana do Livramento (Brasil) o Artigas (R.O.U.) y Quaraí (Brasil). Ambas comunidades aunque compartan una realidad semejante (contacto español-portugués) no son del todo iguales, debido principalmente a su geografía. El contacto entre Rivera y Livramento ocurre a través de lo que se llama frontera seca, puesto que no están separadas por un río, sino por una calle, lo que ocasiona una intimidad mayor entre las dos ciudades, mientras que Artigas y Quaraí están separadas por las aguas del río Cuareim (Quaraí del lado brasileño), lo que aísla, aunque mínimamente, las dos ciudades.

Por más que el contacto entre Rivera y Livramento ofrezca menos obstáculos, la existencia del río Cuareim entre Artigas y Quaraí, una frontera concreta, no impide que ciudadanos de ambos países convivan a diario y compartan una realidad que no es ni brasileña ni uruguaya, sino más bien una realidad de frontera, una realidad propia.

Desde chicos, como ciudadanos nacidos y criados en la frontera (Rivera/Livramento y Artigas/Quaraí), nos acostum-

Sigla de República Oriental del Uruguay. 
bramos a entender la idiosincrasia característica de tales núcleos poblacionales fronterizos. Es decir, estamos acostumbrados al hecho de que en la frontera el uruguayo pueda despertarse y en seguida cruzar el puente o, simplemente, la calle para ir a trabajar del lado brasileño, o viceversa, y que para ello no necesite hacer un visado, o una tarjeta de extranjero.

Sin embargo, como somos testigos, no solo por trabajo se cruzan las fronteras, el amor es asimismo uno de los protagonistas y con él los matrimonios entre brasileños y uruguayos son una rutina. De esas uniones nace un personaje peculiar típico de la frontera, el llamado doble chapa ${ }^{2}$, o sea, aquel individuo que es legalmente uruguayo y brasileño y que convive dentro de su propio hogar con el bilingüismo, hablando muchas veces con su padre en un idioma y con su madre en el otro, convirtiéndose así en un ciudadano naturalmente bilingüe. No obstante, esta no es la única forma de incentivo al bilingüismo o al contacto entre lenguas en la frontera, puesto que es una práctica común en esa región que hijos de brasileños estudien en escuelas uruguayas o al contrario, que los hijos de uruguayos estudien en Brasil.

Como vemos, la frontera afecta de tal forma las dos ciudades que la forman que incluso la economía es muy particular en la región y oscila de acuerdo con la situación financiera y la fluctuación cambial de ambos países, ya que según los precios de ambos, la marcha de compradores cambia constantemente de sentido. Podríamos citar todavía otro aporte muy importante para la interpenetración cultural y lingüística que se da en la frontera Uruguay-Brasil, la presencia de los medios de comunicación de un país en otro y viceversa. A través de ellos, los uruguayos de la frontera tienen acceso a las telenovelas brasileñas así como a los informativos y a todos los demás programas vehiculados en las cadenas de Brasil que acaban por influir muchas veces en sus costumbres, así como los brasileños que pasan a conocer la vida

2 Reciben esta denominación a raíz de que antiguamente los coches de la frontera tenían doble licencia, es decir una chapa con matrícula uruguaya y otra con matrícula brasileña, lo que les permitía transitar libremente por los dos lados de la frontera. 
uruguaya por la pantalla de la tele o por las radios, al escuchar muchas veces más canciones en español que en portugués. Un ejemplo importante de esta interpenetración a través de los medios de comunicación y del producto de la misma es el carnaval de la frontera que ha cambiado mucho en los últimos años. Lo que antes en Artigas y Rivera se caracterizaba por un desfile de

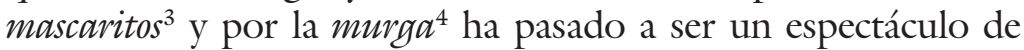
escuelas de samba a imitación de las Escolas de Samba brasileñas, con el detalle de que las letras de las canciones son en portugués y no en español, la lengua nacional. Sin embargo, la samba bailada no es la misma de Río de Janeiro, sino que es una mezcla de esta y del candombe, ritmo uruguayo. Esto es de gran relieve para comprender las actitudes afectivas y culturales de la población fronteriza en relación con una serie de factores, entre ellos la utilización de la lengua portuguesa y de la lengua española.

Por esas razones, el español y el portugués de tales zonas no siguen exactamente los modelos de lengua que se enseñan en las academias de ambos idiomas. Tampoco podemos decir que el español de tales zonas se llame portuñol como quieren muchos de los que no están al tanto de la realidad fronteriza. El portuñol es una interlengua ${ }^{5}$ que surge durante el aprendizaje o el contacto esporádico de español o portugués, y no es lo que ocurre en la frontera puesto que la mayoría de los ciudadanos de allí sabe perfectamente dónde y cuándo puede hacer uso de dicha variedad lingüística. Es decir, el artiguense que llega a Montevideo o que habla con uruguayos de zonas que no tienen contacto con el portugués, sabe adecuar su español a determinado contexto, la variedad de la frontera parece neutralizarse y el hablante asume entonces la norma del español uruguayo patrón. Es decir, el

3 Personas disfrazadas con ropas viejas, sábanas de tal manera que no se pueda descubrir su identidad y que recorren los barrios de las ciudades uruguayas en la época de Carnaval.

4 Se denomina murga a una forma popular de música callejera desarrollada en varios países durante alguna festividad (Carnavales, fiestas patronales, aniversarios de fundación, eventos deportivos, etc.)

5 Según Corder (1981) la interlengua se caracteriza por una mezcla de sistemas lingüísticos que se van sofisticando de acuerdo con el avance en la lengua objeto. 
fronterizo sabe la norma del español y también, en la mayoría de las veces, es consciente de que la referencia lingüística fronteriza tiene valor positivo en su comunidad, pero que no lo tiene en otras donde el contacto con el portugués no es expresivo.

De esta forma podemos decir que tenemos una lengua hablada en Uruguay, el español, y otra hablada en Brasil, el portugués, aunque dentro de ambos países haya subdialectos, como el que encontramos en las fronteras o variedades de las lenguas patrón.

Como afirma Gutiérrez Bottaro (2002), muchos estudios ya se han hecho desde la perspectiva uruguaya sobre la realidad lingüística y sociolingüística de la región fronteriza. A ejemplo de ello tenemos a Elizaincín $(1973 ; 1975 ; 1976)$, uno de los principales investigadores del tema, quien al hablar de la región de frontera Uruguay-Brasil, la define como "bilingüie" y "diglósica". Para el autor, hay variedades de lengua que conviven en la frontera y que gozan de prestigio en determinadas comunidades. Además, hay que considerar, una especie de bilingüismo existente en la misma zona uruguaya de la frontera que se hace presente debido a la utilización de como mínimo dos variedades de diferentes estatus sociolingüísticos: el español y lo que Elizaincín llama DPU, dialectos portugueses en Uruguay, un tipo de constructo donde el modelo fonético se acerca al español, mientras que la morfología y la semántica se acercan al portugués.

Sin embargo, los DPU son típicos de determinadas comunidades de la periferia en el lado uruguayo de la frontera que hacen uso de estos dialectos portugueses como una marca de su identidad, idea defendida por Elizaincín. No obstante, otros autores, afirman que el panorama lingüístico fronterizo incluye asimismo otras variedades tales como el portugués estándar (HENSEY, 1972) o el portugués gaucho de frontera (TRINDADE, BEHARES y FONSECA, 1995). Estamos de acuerdo con Elizaincín incluso cuando se refiere a esta zona como diglósica, ya que, por nuestra experiencia de fronterizos, sabemos que cada una de las lenguas cumple funciones específicas establecidas por la 
sociedad. El español es la lengua oficial en el lado uruguayo, por lo tanto es el idioma utilizado en todas las actividades formales. En cambio, los DPU se utilizan exclusivamente en actividades informales, entre familiares y amigos y mayormente por algunas capas de la sociedad, lo cual le agrega un valor despectivo. Un rasgo interesante de este contacto que podemos observar en la convivencia con el pueblo de la zona fronteriza es que mientras los uruguayos de determinadas comunidades de la frontera intentan reproducir la lengua de sus vecinos lusohablantes lo que los lleva a los DPU, los brasileños siguen hablando el portugués, sin embargo, se incorporan de muchas palabras del español como si fueran de su propia lengua. Los DPU pasan a ser vistos entonces como una identidad de la periferia de estas ciudades y tienen un carácter despectivo para el que no comparte esta realidad, o sea, el uruguayo de regiones sin fronteras internacionales o el de zonas de frontera y la clase dominante, mientras que el portugués con préstamos del español no sufre el prejuicio por parte del lusohablante de la frontera. Un ejemplo de ello vemos en los siguientes enunciados:

1. "Nos semo uruguayo".

2. "Traz o rádio e enchufa na parede".

En el enunciado 1, tenemos un ejemplo de un uruguayo que usa un subdialecto plagado de términos que se asemejan a la lengua portuguesa como si fuera un calco. Es un ejemplo clásico de lo que Elizaincín llama DPU, variedad que, como dicho, goza de poco prestigio e incluso sufre prejuicio entre los hablantes cultos del español estándar de Uruguay, incluso los de la frontera. Ya en el enunciado 2, tenemos a un brasileño fronterizo que incorpora a su vocabulario palabras del español, adaptándolas a la morfología de su propia lengua, es decir, el portugués, creando neologismos en el portugués como el verbo "enchufar" extendido entre los hablantes del portugués de la frontera. A diferencia de lo que ocurre con el uso de los DPU, esta forma de hablar está aceptada por el hablante del portugués culto de esta región y no está marcada por ningún valor negativo en la frontera. 
No obstante, estos no son los únicos ejemplos de alteraciones de la norma que se encuentran en la frontera y sobre todo nos interesa hablar, como profesores de español, de los cambios más sutiles que ocurren en el español de esta zona. Cambios estos que, a diferencia de los DPU, no están considerados como una variedad estigmatizada y se convierten en el modelo fronterizo del español, y que, como defendemos, no se trata de portuñol como lo tildan muchas personas que no tienen conocimiento de la realidad de la frontera y de la noción de lenguas en contacto.

Las diferencias más marcadas entre la variedad fronteriza del español y la norma patrón de la lengua son el régimen preposicional, la morfología de algunos verbos, y, claro está, el vocabulario. Eso se debe a una influencia muy expresiva del portugués en contextos muy similares entre las dos lenguas. Observemos las tablas comparativas que presentamos a continuación:

Tabela 1: Variedades de Lengua Patrón

\begin{tabular}{|c|c|c|}
\hline & Enunciados en $\mathrm{PBP}^{6}$ & Enunciados en $\mathrm{EUP}^{7}$ \\
\hline Uso de Preposición & $\begin{array}{l}\text { Vou } a \text { Porto Alegre de } \\
\text { carro. }\end{array}$ & $\begin{array}{l}\text { Voy a Porto Alegre } \\
\text { en auto. }\end{array}$ \\
\hline Uso de Preposición & $\begin{array}{l}\text { Eu falei para ele que } \\
\text { não. }\end{array}$ & Yo le dije que no. \\
\hline $\begin{array}{l}\text { Morfologia del } \\
\text { Verbo }\end{array}$ & Espero que estejas bem. & Espero que estés bien. \\
\hline Vocabulario & O chuveiro é novo. & La ducha es nueva. \\
\hline Regencia verbal & Eu gosto da professora. & Me gusta la profesora. \\
\hline
\end{tabular}

\footnotetext{
6 Portugués Brasileño Patrón.

7 Español Uruguayo Patrón.
} 
Tabela 2: Variedades del Español fronterizo afectadas por el portugués

\begin{tabular}{l|l}
\hline Diferencias de la Norma & Enunciados en EUF \\
\hline Uso de Preposición & Voy a Montevideo de auto. \\
\hline Uso de Preposición & Dije para él que no. \\
\hline Morfología del Verbo & Espero que esteas bien. \\
\hline Vocabulario & El lluvero es nuevo. \\
\hline Regencia verbal & Me gusta de la profesora. \\
\hline
\end{tabular}

Como podemos ver, la fusión de los dos enunciados de la la tabla 1 , forma la tabla 2 , lo que comprueba la relación singular de las dos lenguas en la frontera y el producto de esta interacción lingüística.

Algunos de los cambios de la tabla 2 son más recurrentes que otros y aunque los hayamos traído como ejemplo, eso tampoco quiere decir que todo uruguayo de la frontera opte por tales cambios, pero cualquiera de ellos no sufriría un estigma por parte de un hablante culto del español de la frontera, pues son cambios que, debido a la convivencia entre portugués y español existente en la zona, no son muchas veces ni siquiera percibidos por estos hablantes y no se muestran tan diferentes de la norma para que sean considerados una nueva lengua o una interlengua como lo es el portuñol en contexto de aprendizaje.

A través de estas pocas líneas, quisimos dar una idea de los factores que influyen en el español hablado en las fronteras Rivera-Livramento y Artigas-Quaraí. Factores estos que crean una nueva realidad lingüística en estas zonas. Observamos que el español de la frontera está influenciado por el portugués, así como las zonas limítrofes de todos los países hispanohablantes tienen marcas características debido al contacto, en mayor o menor grado, con otra realidad social, cultural y lingüística distinta

8 Español Uruguayo Fronterizo.. 
a la suya. Lo que no estamos de acuerdo es que el español de la frontera Uruguay-Brasil sea despectivamente conocido por portuñol porque los hablantes de la frontera están conscientes de su variedad y, la mayoría de ellos, está consciente sobre cómo es el español considerado estándar en Uruguay. Además, los cambios que sufre el español de la frontera, no nos referimos aquí al subdialecto llamado DPU, son demasiado sutiles para que consideremos que la variedad de la zona se oponga a la norma culta. Defendemos, por lo tanto, la valoración de la riqueza lingüística de la frontera como una variedad más de una lengua históricamente tan plural como es el español. Así, defendemos que esta variedad tan familiar en el sur de Brasil y norte de Uruguay, debe ser reconocida por los profesores en el aula de E/LE, a la vez que los mismos deben posibilitar al alumno oriundo de estas regiones el acceso a lo que llamamos español estándar o portugués estándar. Al dar a conocer nuevas realidades no solo el estudiante venido de la frontera estaría creciendo en la clase de español con el estudio del español platense, peninsular, caribeño, etcétera sino que también su profesor y sus compañeros de clase lo harían, teniendo acceso a una realidad nueva, el español fronterizo y su riqueza cultural y lingüística y con él, una nueva forma de actuar en el mundo.

\section{Referências}

APPEL, René; MUYSKEN, Pieter. Bilingüismo y contacto de lenguas. Barcelona: Editorial Ariel S.A, 1996.

BARRIOS PINTOS, Aníbal. Rivera, Una Historia Diferente. Tomo I. Montevideo: Ministerio de Educación y Cultura, 1985.

BARRIOS PINTOS, Aníbal. Rivera, Una Historia Diferente.Tomo II. Montevideo: Ministerio de Educación y Cultura, 1990.

CORDER, S.Pit. The study of interlanguage. In: S.P. Corder. Error analysis and interlanguage. Oxford University, 1981. p. 65-78, 
ELIZAINCÍN, Adolfo; BEHARES, Luis Ernesto; BARRIOS, Graciela. Nos Falemo Brasilero. Dialectos portugueses en Uruguay. Montevideo: Amesur, 1987.

ELIZAINCÍN, Adolfo. Estado actual de los estudios del fronterizo uruguayo-brasileño. In: Cuadernos del Sur, n. 12, p. 119-140, 1979.

ELIZAINCÍN, Adolfo. El español actual en el Uruguay. In: C.Hernández (Coord.). Historia y presente del español de América. Valladolid: Junta de Castilla y León/Pabecal, p. 127-136, 1992a.

ELIZAINCÍN, Adolfo. Dialectos en contacto. Español y portugués en España y América. Montevideo: Arca, 1992b.

ELIZAINCÍN, Adolfo. Las fronteras del español con el portugués en América. In: Revista internacional de lingüística iberoamericana, n. 4, p. 105-118, 2004.

GUTIÉRREZ BOTTARO, S. E. O entreberado, esa língua que inbentemo aqui: O contínuo lingüístico na região fronteiriça Brasil-Uruguai. Dissertação de Mestrado/USP, 2002.

HENSEY, Frederik Gerald. The Sociolinguistics of the Brazilian Uruguayan Border. Mouton: The Hague, 1972.

MORENO FERNÁNDEZ, F. Principios de sociolingüística y sociología del lenguaje. Barcelona: Ariel, 1998.

TRINDADE, A.; BEHARES, L.; FONSECA, M. Educação e Linguagem em Áreas de Fronteira Brasil-Uruguai.Santa Maria: Pallotti, 1995. 